\title{
Saks And The Unholy Trinity: Vendors, The Securities And Exchange Commission, And The Hedge Fund
}

\author{
Teaching and Assessing Critical Thinking Skills in Intermediate \\ Accounting through Unstructured Cases \\ Heidemarie Lundblad, (E-mail: heidemarie.lundblad@csun.edu), California State University, Northridge \\ Barbara A Wilson, (E-mail: barbara.wilson@ csun.edu), California State University, Northridge
}

\begin{abstract}
This paper reports on the use of an unstructured case to teach and assess research, critical thinking, and communication skills in Intermediate Accounting classes. It includes a case specifically prepared for this purpose (an imbedded course measure) and a generic critical thinking assessment form that was customized for this assignment. This assessment process meets AACSB accreditation requirements. Students satisfactorily determined relevant facts, identified the accounting issues, and supported solutions. However, they did not satisfactorily research the authoritative literature or identify appropriate solutions.
\end{abstract}

\section{INTRODUCTION}

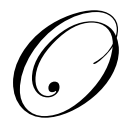

nce it was sufficient for accounting majors to memorize a limited number of standards and learn how to "crunch the numbers." Alas, this halcyon era ended decades ago. Today, accounting firms demand that graduates not only perform traditional accounting tasks, but process information critically: identify accounting issues, research and document the relevant accounting literature, and communicate findings effectively. In addition, AACSB requires that colleges identify specific learning outcomes and assess measures how well these outcomes are achieved. These demands have increased the challenges faced by accounting educators. Teaching and evaluating critical thinking and communication skills is difficult, time consuming and, many accounting educators fear, detracting from the primary mission: teaching accounting rules. It is little wonder then that many accounting faculty shy away from critical thinking assignments. This paper discusses the approach used at California State University, Northridge (CSUN) to enhance and assess critical thinking skills and enhance students' knowledge of accounting without overwhelming the instructor. This approach also satisfies AACSB assessment requirements.

\section{LITERATURE REVIEW}

Accounting education has been under pressure to change its current teaching methods. Over the past decade, accounting programs have incorporated writing assignments into the curriculum and reinforcing the importance of writing in response to the mandates by the AICPA, the major accounting firms, and the CPA examination requirements (Catanach Jr. \& Rhoades, 1997). Yet, many college graduates still lack critical thinking skills. Derek Bok (2005), president of Harvard University from 1971 to 1991, states in his book, Our Underachieving Colleges, that although professors regard improving critical thinking as the most important goal of college, tests reveal that between their freshman and senior year, students who begin their studies with average critical thinking skills have progressed only from the $50^{\text {th }}$ percentile to about the $69^{\text {th }}$ percentile. 
Critical thinking skills continue to be the most sought after skills by accounting firms. Burnett (2003) surveyed employers of their university's accounting graduates and members of a local CPA chapter. The top-rated four professional skills were analytical/critical thinking, written communication, oral communication, and decision making. These skills correspond to the Accounting Education Change Commission's (AECC) Position Statement Number One (1990). Accordingly, accounting students must be taught communication and analytical skills - the ability to locate, obtain, and organize information and the ability to confront and solve unstructured problems in unfamiliar settings, and to exercise judgment based on comprehension and an unfocused set of facts.

Bradley (1998) investigated the linkage between cognitive reasoning and performance in ill-structured tasks. An ill-structured ${ }^{1}$ problem/task is either somewhat novel for the individual problem solver (lack of content-specific information in long-term memory), or there is a diversity of opinion process among the professionals regarding the solution. In addition the solution of an ill-structured problem requires more inductive reasoning - search for relevant information, comprehension of the material, and ability to evaluate the solution.

Several researchers (Basu \& Cohen, 1992; Catanach \& Rhoades 1997; Gabriel \& Hirsch, 1992; Hanson, 2006) have found that a writing assignment provides an opportunity for students to improve their analytical and critical writing abilities and research skills. Furthermore, instead of a single assignment, instructors should also consider using several one-or two-page writing exercises that are relevant according to practitioners and corporate accountants. Assignments might include questions dealing with revenue recognition, financial instruments, or disclosure issues.

In addition to using ill-structured tasks to teach critical thinking, there is a need for evaluation techniques to evaluate critical thinking (Sormunen \& Chalupa, 1994). Several researchers (Baron, 1987; McPeck, 1981; Sormunen \& Chalupa, 1994) suggest gathering baseline information with periodic evaluations to determine whether performance is sustained over time. Educators must also evaluate whether skills (knowledge) is transferred from one situation to another in other courses.

The case we used for the assessment process described here fits Bradley's definition of an ill-structured problem because students had only a small amount of related information stored in long-term memory, and had to solve the problem in a controlled manner employing methods such as means-end analysis -identifying the goal, the current facts, and the solution (Bradley, 1998). Evaluation of critical thinking development is related to the contentfacts, concepts, and principles (McPeck, 1981). The assignment also required students to use a writing-to-learn approach. They had to analyze, synthesize, and organize information to effectively communicate it to a particular audience (Catanach Jr. \& Rhoades, 1997).

At CSUN accounting students are taught communication and research skills and are introduced to critical thinking concepts in an accounting communication course taken in conjunction with the first intermediate accounting class. However, as discussed above, skills introduced in one course must be reinforced in following courses. This paper describes how an unstructured case is used in the second intermediate accounting course to evaluate how well students retained the skills learned in preceding courses.

The remainder of the paper is organized as follows: Part I contains the instructional case. Part II discusses how the case is used to assess the extent to which students use research, critical thinking and communication skills that were taught in previous courses. It includes a discussion of the results and how they are used to provide feedback to instructors of the earlier courses for continuous improvement.

\section{PART 1: THE CASE}

Saks And The Unholy Trinity: Vendors, The Securities And Exchange Commission (SEC), And The Hedge Fund

\footnotetext{
${ }^{1}$ Bradley uses the term "ill-structured" problem, while we use the term "unstructured" case. We believe the two terms refer to the same type of problem.
} 
“Saks Offers to Buy Back Over Half of Its Bonds” (Esterl, June 21, 2005, p. 1)

Saks Fifth Avenue (Saks) is one of the most famous names in US fashion retailing. Its landmark store on Fifth Avenue in New York has long been a leading destination for discerning shoppers. The company was founded in 1924 by Horace Saks and Bernard Gimbel. Over time, it grew to 57 stores located in major cities from coast to coast. Saks also operates a number of outlet stores under the name "Off Fifth."

In 1998 Saks was acquired by Proffitt's Inc., a department store chain based in Atlanta, Georgia. At the time, Proffitt's already owned several other clothing and/or department store chains in the South and Mid-West: Parisian, Carson Pirie Scott \& Co., Boston Stores, Bergner's, Herberger's, and Younkers. A recent acquisition is Club Libby $\mathrm{Lu}$, a chain that markets to girls in the "tween" years. After the merger, Proffitt's changed its corporate name to Saks Incorporated. As of 1998, the company's stock is traded on the New York Stock Exchange under the symbol SKS (Saks, Inc., 2006).

However, in 2005, Saks made news for certain non-fashion related reasons, which eventually led to the events described below.

On June 20, 2005, the company announced an offer to repurchase about half of its $\$ 1.22$ billion in publicly traded debt. Specifically, it offered to buy $\$ 658$ million of notes at 99 . These notes had maturity dates of 2010, 2013, 2019. At the time they had been trading at less than par. Saks also offered to pay $\$ 1$ for each $\$ 1,000$ to holders of bonds that are maturing in 2008, 2011, and 2024. These bonds were trading above par.

On June 24, 2005, Saks amended its original offer. Under the amended tender offer, the bonds maturing in 2010, 2013, 2019 would be repurchased at par. Included in the repurchase price is a \$20 consent payment per individual $\$ 1,000$ bond (SEC, 2005).

At the time of the tender offer, Saks had ample cash reserves, partly as the result of the sale of the Proffitt's chain for $\$ 620$ million. As of August 2005, the company had cash reserves of $\$ 324$ million and unused credit lines amounting to $\$ 650$ million (Saks, 2005).

Why did Saks decide to repurchase about half of its outstanding bonds and offer cash inducements to the remaining bondholders? The following information may shed light on the company's motivation:

1. A number of vendors filed suits against the company claiming that it has been improperly collecting vendor allowances. Saks was also charged with improperly imposing penalties for the following: Markdown allowances, alleged short shipments, late deliveries, mismarked merchandise, and improper packing (Byron, June 18, 2005).

2. The SEC investigated possible vendor accounting irregularities (Byron, June 6, 2005).

3. Saks Inc. delayed required quarterly SEC filings because of the need to investigate and defend the allegations.

4. A major holder of Saks Inc. convertible bonds, Highbridge Capital Management (a hedge fund), filed a notice of default (Esterl, June 21, 2005).

Based on the information above, the references listed at the end of the case, and your research, complete the following assignment. Research the issues outlined below and write a one-page memo in which you explain the following:

1. Why did Saks offer to repurchase the notes (bonds)?

2. Saks seems to have plenty of cash to make required interest payments and has no record of missing interest payments. Why then, was a "notice of default" issued?

3. From an accounting point of view, explain what it means if a "notice of default" is filed.

4. How should the repurchase of notes and payments to bondholders be treated?

5. What are the accounting issues that are being investigated by the SEC? 
In your memo make sure to reference the appropriate accounting standard(s) and/or Security Law or SEC standard(s) that apply to this case. Your memo should include a sample journal entry to illustrate the proper accounting of the repurchase of the bonds. Finally, the memo should be prepared in accordance with the instructions you received in Intermediate Accounting 351 (ACCT 351) and Accounting Communications 351COM (ACCT $351 \mathrm{COM})$.

Write your memo to Samuel Locker, your manager at Adams and Becker, \& Co. He has been following the news about Saks in the Wall Street Journal and the investigation by the SEC. He is interested in your research findings for defaulting on technical bonds because several of the firms' clients have public debts with notes maturing over the next ten years.

\section{PART II: USING THE CASE TO REINFORCE AND ASSESS RESEARCH, CRITICAL THINKING AND COMMUNICATION SKILLS IN INTERMEDIATE ACCOUNTING}

One of the authors wrote this case specifically for use in an Intermediate Accounting class to illustrate a real technical bond default situation and how it was handled by the company. The case was also used to assess students' research, critical thinking, and communication skills.

In two prerequisite courses (ACCT 351 and adjunct ACCT 351COM) students learn how to research the accounting literature (i.e., the Financial Accounting Research System (FARS) and to communicate in a manner appropriate for accounting professionals. It is expected that the skills acquired in these courses will be practiced and reinforced in subsequent accounting courses. One way to accomplish this is through the assignment of unstructured (ill-structured) cases across the curriculum. The case presented above is reasonably unstructured, and it is open ended but narrowly focused on accounting for corporate bonds in default. The case served as a component of the normal (graded) class assignments and as an imbedded course measure to assess whether course learning goals are being achieved.

\section{The Saks Case: A Component Of The Normal (Graded) Class Assignments}

The case was used to evaluate students' ability to analyze, research, and effectively communicate findings directly related to a subject covered in the course (accounting for corporate bonds). Specifically, students must research the following accounting and financial reporting issues:

1. Reporting requirements for the correct classification of bonds in default.

2. Treatment of technical default (versus default caused by non-payment)

3. $\quad$ Early retirement of the bonds placed in technical default.

4. Treatment of "consent payments' offered to bond holders who agreed not to demand acceleration of payment on the firms remaining bonds.

Students must suggest appropriate alternative accounting treatments and prepare sample journal entries to illustrate their recommendation. Also, they must justify the recommendation with appropriate references to accounting standards. Some of the issues addressed by the case are part of the ACCT 352 curriculum - the correct classification of bonds in default. Some of the issues, however, require students to go beyond the textbook and conduct additional research. For example, the "consent payments" offered by Saks and causes and effects of a technical default are topics not usually addressed in undergraduate textbooks. Including such topics in the case requires students to use analytical and research skills that go beyond simply reading a textbook.

\section{The Saks Case: A Tool To Assess Whether Course Learning Goals Are Being Achieved}

The College of Business and Economics at CSUN has established a formal assessment program in conformity with AACSB requirements. Each course must specify subject specific as well as general learning goals and assess how well these learning goals are met. Assessment can be an extremely time consuming activity; however, 
the same assignment (the Saks case, for example) can be used to test students' knowledge of course related material and assess course learning goals. Consequently, the assignment was graded by the instructor and contributed to the overall grade students received for the course. Additionally, a random sample of papers was used to separately assess the following learning goals in three sections of the second Intermediate Financial Accounting course (ACCT 352).

\section{ACCT 352 COURSE OBJECTIVES}

The accounting specific learning objectives include:

1. Each student conceptually understands external financial reporting.

2. Each student can apply conceptual understanding of external financial reporting to real world problems.

3. Each student can research the professional literature (i.e., the FARS database) in external financial reporting.

Additionally, the class focuses on two general learning goals:

1. Each student can apply critical thinking skills when analyzing and solving accounting problems.

2. Each student can effectively communicate complex accounting concepts in writing.

As was mentioned in the introduction, many accounting professors are reluctant to use writing assignments because of the perceived difficulty of effectively, efficiently, and fairly grading such assignments. In this particular case, for example, one instructor had to read and grade one hundred and ten papers. Depending on funding and staffing possibilities, graders could help with this task. However, significant training might be required, particularly where there is a limited supply of available graduate students. To ameliorate the grading burden and ensure consistency across evaluators, a grading rubric was developed, based on a generic critical thinking assessment form (Appendix A) that has been developed by the CSUN accounting faculty. This instrument was customized for the Saks, Inc. case to include the specific technical items that should be addressed by students (Appendix B). Each section of the form also included point values for grading purposes. Having such an instrument significantly reduces the amount of time required to grade technical papers and, with some additional training, can easily be used by a teaching assistant.

\section{Assessment Results}

Of 110 students who completed the assignment and received a grade in ACCT 352, 30 student papers were selected randomly for assessment.

Five faculty members served on the assessment team: the course instructor, two other faculty members who teach Intermediate Accounting, and two faculty members who teach Accounting Communications. The same customized assessment form (Appendix B) that was used for grading the case was also used for the assessment process.

One team member served as a facilitator and led a norming process using three papers selected from the sample. After agreement on evaluation and ranking of these three papers, the remaining 27 were evaluated by the team: each person on the team evaluated approximately 5 papers.

Appendix C contains the assessment results. Almost $90 \%$ of the students were able to determine the relevant facts, $70 \%$ identified the correct accounting issues, and $70 \%$ were able to state and support solutions (authoritative schedules and appropriate journal entries). This demonstrates that a majority of students understand conceptual issues in financial accounting, but the scores also show that performance on two factors was unacceptable: Seventy percent of students failed to research the authoritative literature and/or properly document the accounting literature, and $67 \%$ failed to identify solutions and alternatives (if appropriate) for some issues. 


\section{DISCUSSION}

The students' overall failure to properly research and/or document the accounting literature was a disappointment, especially since students had been taught how to do so in the preceding courses-ACCT 351 and 351COM. In ACCT 351COM students are taught how to properly research the authoritative literature and communicate and document their findings. In fact, the same students were assessed the previous semester in ACCT 351 using an unstructured case with encouraging results: 70\% properly researched and documented the accounting literature. However, using a similar unstructured case, it was apparent that students did not transfer some of the skills from ACCT 351 to ACCT 352.

Even more distressing, many apparently did not understand that skills learned in previous courses are requirements for succeeding courses (let alone the "real world"). Feedback from students supports this statement. For example, when the ACCT 352 instructor raised this subject in class and indicated that failure to research and/or document the appropriate authoritatively accounting literature resulted in lowered grades, students expressed surprise that researching and documenting the literature is required professionally, not just in ACCT 351 and 351COM.

The 351 team discussed the ACCT 352 assessment findings and agreed that the students' research skills needed improvement. For spring semester 2006, the ACCT 351 and ACCT 351COM faculty will shift from a teacher-centered to a student-centered approach. In other words, instead of the faculty providing the appropriate sources, the faculty will facilitate/guide students' research attempts. Students will be encouraged to examine their research strategies and broaden the scope of search techniques when their results lack relevance. Faculty will help the students to seek alternative methods during the research process.

Students' failure to identify appropriate solutions indicates difficulties with applying conceptual understanding to real world problems. This was disappointing because the previous semester showed that $98 \%$ of the students identified a solution. After much discussion, the ACCT 351 instructors decided on less guided instruction throughout the semester. Specifically, students will have to develop their own schemas for analysis of the last two cases - procedural knowledge that will enable them to process information and apply conceptual knowledge in the "real world." Furthermore, students in ACCT 351 will attach the critical thinking generic template to their assignments so that they understand that this is how their papers will be evaluated.

Assessment results were somewhat disappointing but they provided valuable empirical evidence that research, critical thinking, and communication skills need to be taught in more than one course. They must be practiced and reinforced in all courses. The assessment process provides valuable feedback to instructors on how well students meet course goals. Discussions of assessment results by department members generated recommendations for changes in teaching methods to ensure continuous improvement. Finally, the customized assessment (grading) form proved highly successful and is easily adapted to other courses.

This paper reported on the experiences in one course, however, the assessment methodology is easily adapted to other courses and/or subjects.

\section{REFERENCES}

1. Accounting Education Change Commission (AECC). (Fall, 1990). Objectives of education for accountants: Position Statement Number One. Issues in Accounting Education, 5, 307-312.

2. Baron, J. (1987). Evaluating thinking skills in the classroom. In J. Baron \& Sternberg (Eds.), Teaching thinking skills: Theory and Practice, 221-248. New York: Freeman.

3. Basu, P. \& Cohen, J. (Fall 1994). Learning to learn in the accounting principles course: Outcome assessment of an integrative business analysis project. Journal of Accounting Education, 12, 359-374.

4. $\quad$ Bok, D. (2005). Our underachieving colleges. Princeton University Press.

5. Bradley, W. E. (1998). Accounting expertise and ill structured problems: Cognitive reasoning abilities and performance in business valuation tasks. Dissertation: AAT 9920317. University of Arkansas.

6. Byron, E. (June 6, 2005). Saks Studies Booking of Allowances. The Wall Street Journal, B10. 
7. Byron, E. (June 18, 2005). Saks Sued Again For Withholding Markdown Money. The Wall Street Journal, B4.

8. Burnett, S. (Jan/Feb 2003). The future of accounting education: A regional perspective. Journal of Education for Business, 78, 129-134.

9. Catanach Jr., A. H. \& Rhoades, S. C. (Fall 1997). A practical guide to collaborative writing assignments in financial accounting courses. Issues in Accounting Education, 12, 521-537.

10. Esterl, M. (June 21, 2005). Saks Offers to Buy Back Over Half of Its Bonds. The Wall Street Journal, C5.

11. Gabriel, S. L. \& Hirsch, Jr., M. L. (1992). Critical thinking and communication skills: Integration and implementation issues. Journal of Accounting Education, 10, 243-270.

12. Hanson, J. D. (2006). Using problem-based learning in accounting. Journal of Education for Business, 81, 221-224.

13. McPeck, J. (1981). Critical thinking and education. New York: St. Martin's.

14. Saks, Inc. (2005). Investor Relations, Annual Report. 10K filing. Retrieved from http://www.saksincorporated.com on July 25, 2006.

15. Saks, Inc. (2006). About Us: Our history. Retrieved from http://www.saksincorporated.com/ on July 25, 2006.

16. Securites and Exchange Commission (SEC). (June 20, 2005). Offers to purchase and consent solicitations statement. Saks, Incorporated. \$680,105,000. Retrieved from http://www.sec.gov/Archives/edgar/data on July 25, 2006.

17. Sormunen, C. \& Chalupa, M. (Jan, 1994). Critical thinking skills research. Developing evaluation techniques. Journal of Education for Business, 39, 172-177. 
APPENDIX A

Generic Critical Thinking Evaluation Form

\begin{tabular}{|l|l|l|l|}
\hline \multicolumn{1}{|c|}{ Factor } & Not Acceptable & Acceptable & Above Average \\
\hline Determine the Relevant Facts & & & \\
\hline Identify Accounting Issues & & & \\
\hline Research authoritative literature & & & \\
\hline Identify solution (alternatives if appropriate in circumstances) & & & \\
\hline $\begin{array}{l}\text { State and support solution (Making authoritative schedule, JE, } \\
\text { as appropriate) }\end{array}$ & & & \\
\hline
\end{tabular}

1) Determine Relevant Facts: (Critical thinking-reason)

a) Student sorts relevant material from irrelevant materials

b) Student separates opinions from facts

c) Student identifies need to collect data

2) Identify Accounting Issues (Critical thinking-reason \& understanding conceptual material)

a) Student understands the transaction or events

b) Student recognizes items not stated: unperformed duties, hidden contingencies

c) Student classifies the issue into a broad category: revenue recognition, matching, etc.

3) Research Authoritative Literature (Research \& critical thinking -reason)

a) Student researches GAAP and doesn't discuss tax requirements

b) Student researches the issue identified in item 2

c) Student seems to understand the standards researched

d) Identify \& State Solution (Critical thinking-understand multiple perspectives \& applying conceptual understanding)

e) States a clear solution that a client can understand; or

f) Identifies alternative ways to treat if appropriate.

g) Provides supporting statement for conclusion or alternatives that summarizes logic.

4) Support solution (Critical thinking-evaluate \& applying conceptual understanding)

a) Uses material from case, compares to literature

b) Defends solution and /or plausible alternatives clearly with judgment that is based on accounting literature/concepts. (Analyzes deeply enough that each portion of the research is tested, e.g. if extraordinary event needs to be material, unusual, and infrequent, student tests items against all three.)

c) Develops necessary supporting schedules, recommends correct journal entry as appropriate.

d) Organizes thoughts in a logical order demonstrating deductive or inductive reasoning. 
APPENDIX B

Customized Critical Thinking Assessment Form for the Saks, Inc. Case

Determine the Relevant Facts

1. Notice of default on bonds

a. Violation of indenture agreement (Q. 2; Q. 3)

2. Offer to repurchase bonds (Q. 1)

3. Offer of "consent payment"

Background facts - not strictly related to bond repurchase offer

4. investigation by SEC (Q. 5)

5. law suits by vendors (Q. 5)

6. need to restate financial statements (Q. 5)

7. late filing of quarterly financial statements (Q. 5)

Identify Accounting Issues

1. Bond classification (current/non- current Need to reclassify because of default notice

2. Early retirement of long term debt

3. Treatment of "consent payment"

4. Inventory mark-ups, etc. (underlying, minor)

Research authoritative literature (Q.3)

1. Classification of long term obligations Callable by creditor FAS 78, II 5; 13 (Q. 3); L 35 (101); EITF 8630

2. Retirement of long term obligations FAS 76; APB 26 (superseded by FAS 76) FAS 140; FAS 145 (rescission of FAS 4) (Q. 1); FAS 15 (troubled debt restructuring) not applicable (EITF 02-4)

3. Expense recognition SFAC 5 (Q. 1)

4. Bond indenture - Delayed filing of financial statements - Securities \& Exchange Act of 1934 (Q. 2) (minor point)

Identify solution (alternatives if appropriate) Q4 Repurchase bonds/ not repurchase

Recognize consent payment

1. as expense

2. as part of repurchase payment (affect gain/loss on repurchase of bonds)

State \& support solution (Making authoritative schedule, JE, as appropriate)

1. Journal entry to record early retirement of bonds and "consent payment"

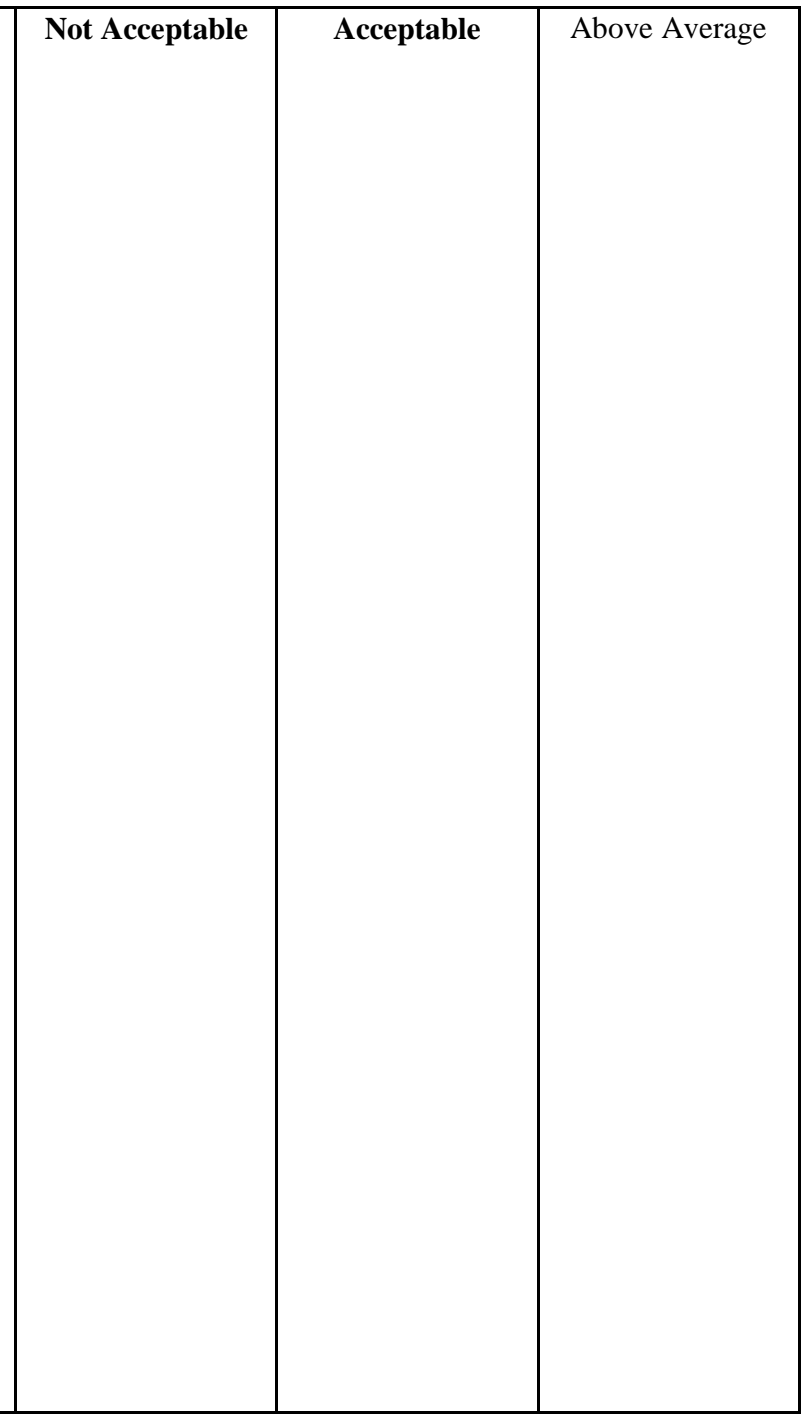


APPENDIX C

Saks Critical Reasoning Assessment, Fall Semester, 2005

(Population -- 110, Sample Size -- 30)

Factor Goals

\begin{tabular}{|l|c|c|c|c|c|c|}
\hline \multirow{2}{*}{ Goal: } & \multicolumn{2}{|c|}{ Not acceptable } & \multicolumn{3}{c|}{ Acceptable } & \multicolumn{2}{c|}{ Above Average } \\
\cline { 2 - 7 } & $\mathbf{N}$ & \% of sample & N & \% of sample & N & \% of sample \\
\hline Determine the relevant facts & 4 & $13.3 \%$ & 23 & $76.7 \%$ & 3 & $10.0 \%$ \\
\hline Identify Accounting Issues & 9 & $30.0 \%$ & 20 & $66.7 \%$ & 1 & $3.3 \%$ \\
\hline Research authoritative literature & 21 & $70.0 \%$ & 8 & $26.7 \%$ & 1 & $3.3 \%$ \\
\hline Identify solutions (alternatives if appropriate) & 20 & $66.7 \%$ & 9 & $30.0 \%$ & 1 & $3.3 \%$ \\
\hline State and support solutions & 9 & $30.0 \%$ & 20 & $66.7 \%$ & 1 & $3.3 \%$ \\
\hline
\end{tabular}

\section{Analysis of Factor Score per Learning Goals}

\begin{tabular}{|c|c|c|c|c|c|c|}
\hline \multirow{2}{*}{ Analysis of Factor Score per: } & \multicolumn{2}{|c|}{ Not acceptable } & \multicolumn{2}{|c|}{ Acceptable } & \multicolumn{2}{|c|}{ Above Average } \\
\hline & $\mathbf{N}$ & \% of sample & $\mathbf{N}$ & $\%$ of sample & $\mathbf{N}$ & \% of sample \\
\hline \multicolumn{7}{|l|}{ Critical Thinking - Reasoning } \\
\hline Determine the relevant facts & 4 & $13.3 \%$ & 23 & $76.7 \%$ & 3 & $10.0 \%$ \\
\hline Identify Accounting Issues & 9 & $30.0 \%$ & 20 & $66.7 \%$ & 1 & $3.3 \%$ \\
\hline Research authoritative literature & 21 & $70.0 \%$ & 8 & $26.7 \%$ & 1 & $3.3 \%$ \\
\hline \multicolumn{7}{|l|}{ Critical Thinking - Evaluation } \\
\hline Identify solutions (alternatives if appropriate) & 20 & $66.7 \%$ & 9 & $30.0 \%$ & 1 & $3.3 \%$ \\
\hline \multicolumn{7}{|l|}{$\begin{array}{l}\text { Ability to research the financial accounting } \\
\text { literature }\end{array}$} \\
\hline Research authoritative literature & 21 & $70.0 \%$ & 8 & $26.7 \%$ & 1 & $3.3 \%$ \\
\hline \multicolumn{7}{|l|}{$\begin{array}{l}\text { Understand conceptual issues in financial } \\
\text { accounting }\end{array}$} \\
\hline Identify Accounting Issues & 9 & $30.0 \%$ & 20 & $66.7 \%$ & 1 & $3.3 \%$ \\
\hline \multicolumn{7}{|l|}{$\begin{array}{l}\text { Apply conceptual understanding to real world } \\
\text { problems in financial accounting }\end{array}$} \\
\hline Identify solutions (alternatives if appropriate) & 20 & $66.7 \%$ & 9 & $30.0 \%$ & 1 & $3.3 \%$ \\
\hline State and support solutions & 9 & $30.0 \%$ & 20 & $66.7 \%$ & 1 & $3.3 \%$ \\
\hline
\end{tabular}

